\title{
The Capability and Social Justice Theories: Developing a Second-Generation Model for Enhancing Epistemological Access in Flood-Prone Schools in Kenya
}

\author{
${ }^{*}$ Gloria Erima \\ Faculty of Education, University of Johannesburg, South Africa \\ https://orcid.org/0000-0003-0399-2255 \\ Felix Maringe \\ Wits School of Education, University of the Witwatersrand, South Africa \\ https://orcid.org/0000-0002-7992-9079
}

\begin{abstract}
This paper draws from a larger doctoral study, conducted between 2013 and 2016 in five flood-prone schools of the Budalang' $i$ division of western Kenya. The mixed-methods study was based on empirical data drawn from twenty-three in-depth interviews from parents, senior school managers, and Sub County Education officers. Fifteen of these interviews were with males and eight with females. A questionnaire was completed by a total of 191 Standard Eight pupils, $49.2 \%$ boys and $50.8 \%$ girls across the five schools. Focus group discussions (FGDs) consisting of ten pupils from each of the five schools were also conducted. The study investigated the extent to which floodprone schools can generate equitable epistemological access (EEA) and how they are committed to delivering a socially just educational experience. The research was embedded in the 'critical realism framework' as the overarching philosophy, premised on Sen's capability approach and Nancy Fraser's social justice framework. The two theories offer competing predications that: 1) the development of individual capabilities improves lives 2) the development of individuals should be based on a socially just approach. Findings suggested that to develop individual capabilities, schools need to embark on a socially just approach, especially to learners who are subjected to deprivation. The paper models a capabilities and social justice approach, as a substantial contribution to our understanding of the extent to which flood-prone schools of Kenya may improve individual capability development. Apart from its implications for policy, we suggest that the model should be implemented in schools to determine its efficacy.
\end{abstract}

Keywords: assessment; capability approach; social justice theory; epistemological access; equity

*Corresponding author: Gloria Erima, erimaglo@gmail.com 


\section{Introduction and Background}

There seems to be a potentially strong and mutually enhancing relationship between Sen's capability approach and education (Terzi, 2007). The capability and social justice arguments remain at the centre of the debate around epistemological access (EA) in multi-deprived schools. Central to this debate is the whole question of schools ensuring the development of individual capabilities among all learners. However, some learners are subjected to deprivations, bringing about a key argument on capabilities and social justice (Erima, 2017). Therefore, when schools develop individual capabilities, they need to ensure that, in so doing, they embark on a socially just approach.

The purpose of this paper is to show theoretical evidence that the heart of achieving EA lies within Sen's capability approach (development of capabilities) and Nancy Fraser's social justice theory (a socially just environment). We argue that the development of learner capability does not mean access to a place of schooling only, but equal access to quality education. The skills and knowledge acquired through education serve as a precursor to a decent life and, subsequently, to influencing the world (Du Plooy \& Zilindile, 2014). Therefore, schooling becomes a basic need for all children who need to be promoted through equal education for all (EFA) and equitable epistemological access (EEA). Working within the social justice and capabilities lenses, the paper develops a debate around an overall conceptual understanding of how EA in flood-prone schools can be understood in relation to the extent to which it fosters key capabilities that individuals, communities, and society, in general, have reason to value (Tikly \& Barrett, 2011). To that end, this paper seeks to answer the questions:

1) What human capabilities do schools in flood-prone areas serve and not serve in Kenya?

2) How might a socially just pedagogy enhance human capabilities in flood-prone areas in Kenya?

\section{Empirical Evidence}

Drawing principally on the ideas of Amartya Sen's capability approach and Nancy Fraser's social justice framework, the study used empirical evidence of the two approaches as tools for analysing and understanding the effect of floods in achieving EA in schools. In doing so, the study identified nine common indicators from literature likely to undermine learning within the context of floods, which constituted the conceptual framework of the research. These indicators are: timeon-task, resources, teaching methodology, instructional leadership, teacher motivation, parental involvement, school communities, the community/environment and culture (Erima, 2017).

The purpose of this research is in line with McLean and Walker (2012). The authors contend that the capability approach conceptualises people living in any form of marginalisation as being deprived of opportunities to make choices for capabilities and functionings that comprise a healthy and dignified life (McLean \& Walker, 2012, p. 585; Walker, 2008). What should not be ignored is that the more 
the wide range of barriers to learning is not overcome or reduced, children in multi-deprived may not benefit from education, which might generate lifelong failure in line with their capabilities and functionings (Erima, 2017). Relevant research including that of Masese et al. (2012), Okuom et al. (2012), Achoka and Maiyo (2008) has been undertaken on what support is/should be given to pupils in flood-prone areas to enrol in schools. Unfortunately, there is little information on the acquisition of learning skills by these pupils. All other factors remaining equal, and despite the Free Primary Education (FPE), 1.8 million children are out of school owing to weather factors (Okuom et al., 2012; Munyi \& Orodho, 2015).

\section{Research Questions}

The doctoral study sought to answer the broad research question: How might equitable epistemological access (EEA) be achieved in flood-prone schools in Kenya? The question was driven by three sub-questions: a) How do schools in flood-prone areas promote physical access? b) How do schools in flood-prone areas promote epistemological access? c) In what ways do different school communities perceive strategies to be effective in promoting epistemological access? The overall aim of the research study was to explore how (equitable) epistemological access [(E)EA] may be achieved in flood-prone primary schools in western Kenya. The assumption was that learners in flood-prone schools experience challenges in developing capabilities from a socially just lens.

\section{The problem}

Formal schooling is key in determining the skills of an individual and plays an influential role in determining his/her life chances as adults (Glewwe, 2002; see also Maina \& Maringe, 2020). Though other factors including parents', friends', and individual abilities also contribute, schools occupy a special role as they are most directly affected by public policies (Munyi \& Orodho, 2015). Children's prospects for EA to basic education depend largely on their access to what type of schooling, and on what basis (Pendlebury, 2009).

Several empirical research works define education access, its challenges, and how it can be achieved in flood-prone schools in Kenya, but explore less about the potential relationship between capability and functioning in education (i.e. EA beyond the basic school functioning). There is little research that seems to look holistically at the capabilities and functionings of children in disadvantaged schools under the umbrella of social justice. The focus has been on segmented areas of physical and epistemological access under basic school functioning (Erima \& Maringe, 2020). Our purpose is to have a suggested model, that incorporates a learning environment in flood-prone schools in Kenya that is appropriate for developing capabilities beyond access, using a socially just approach. The model intends to address issues on a) what human capabilities these schools serve and do not serve, and b) how a socially just pedagogy might enhance human capabilities in this context.

\section{Key elements of Sen's capability approach Capabilities and the notion of agency freedom}

The capability approach focuses on what people can be and do, personally and in comparison to others, to generate reflective, informed ways of living that each 
individual deems important and valuable (Sen 2017; Saito, 2003; Walker, 2008; Alkire, 2013). This, according to Sen, has to do with freedom and how such freedom enhances the ability of people to help themselves and also influence the world, which points to matters that are central to the process of development (Miletzki \& Broten, 2017)). This implies that each person is a 'source of agency' and worth in their own right, with their plans and their own lives to live,' (Cheng, 2017). Therefore, the capability approach takes seriously the development of every person as an end in themselves and not as the means to some other end, such as economic development. Knowledge and skill acquisition would be judged according to how it increased our well-being and agency to live a flourishing life, with genuine choices (Walker, 2008).

\section{Capabilities and educational equality}

Since there exists a potentially strong and mutually enhancing relationship between human capital and human rights in education, it becomes difficult to discuss the two dimensions without bringing in educational equality. This idea is fundamentally grounded in the egalitarian principle that social and institutional arrangements should be designed to give equal consideration to all (Terzi, 2014). This exposes an analysis of the distribution of inputs and how these facilitate the development of key capabilities. This is because equality in education is mainly theorised along the 'divide' between equal input (however defined) and equal outcome while emphasising the importance of context. In this regard, the extent to which the needs and rights of different groups are recognised in education; how decisions about education quality are governed; and the nature of participation at all levels need to be relooked (Tikly \& Barrett, 2011).

\section{Capabilities and the quality of education}

The difference between a capability and functioning is like one between an opportunity to achieve and the actual achievement; i.e. the difference between potential and outcome (Tikly \& Barrett, 2011). This has implications for the way that education is understood and evaluated. A key role for a quality education becomes one of supporting the development of autonomy and the ability to make choices in later life, rather than simply providing individuals with the necessary resources to learn (Erima, 2017). The key arguments of social justice consider education as a human right, which must be provided based on a socially just approach. The quality of distribution should be equitable so that people can have the same kind of opportunities and freedom to choose the kind of lives they want to live (Fraser, 1999). Educational evaluations need not be pegged only on inputs like teachers, hours in class, learning material, outputs, or earnings from a particular level of education (Unterhalter, 2007; Tikly \& Barrett, 2011). Rather, evaluations should look at a) the condition of being educated; $b$ ) the negative and positive freedoms that sustain this condition; and c) ways in which this education supports what every person has reason to value. Capabilities looked at in this way become a basis for assessing quality and not simply access to resources or equality of outcomes (Tikly \& Barrett, 2011), see Figure 1 (Erima,2017). 


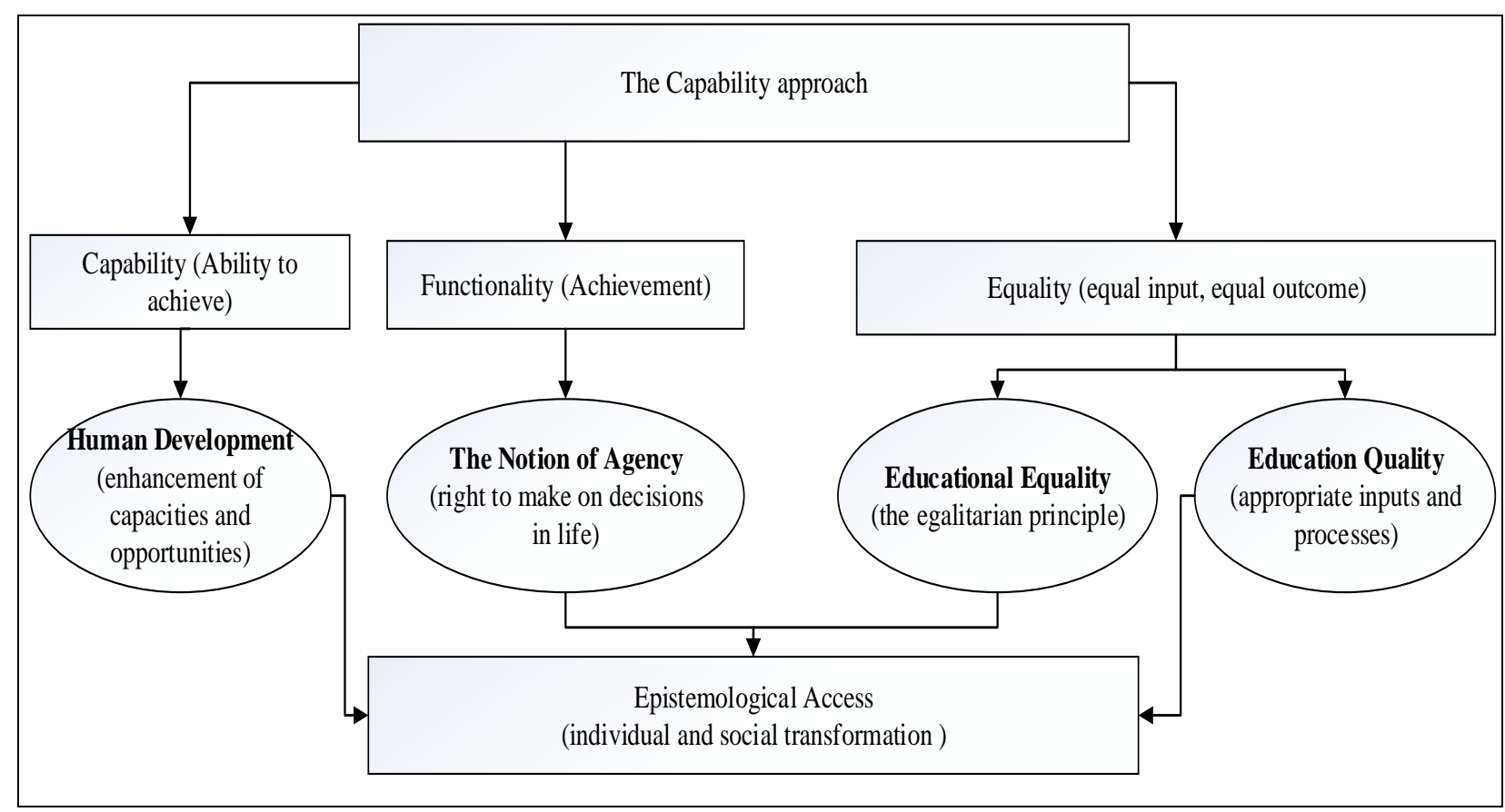

Figure 1. A Conceptualisation of the Capability Approach

Nancy Fraser's Social Justice framework - Assumptions and Key Arguments Because the capability approach (Sen 2002; Nussbaum 2001) is viewed potentially as a robust framework for social justice in education, we draw on the social justice theory, which integrates justice into equality of capabilities and equal valuing of individual diversity. This is mainly because both theories share a commitment to equality in opportunities (Saito, 2003) and would sufficiently frame the debate on (equitable) EA, based on human capital (capabilities) and human rights approaches (social justice) (Tikly \& Barrett, 2011). The idea of quality and equity in education then invites us to attend to questions of social justice for pupils in disadvantaged schools. Nancy Fraser argues for equal opportunities for all eligible children through quality public schooling, for the simple reason that some people do economically better than others and can access better education facilities. Uneven distribution of resources results in large-scale inequalities. Societies wherein life chances are not distributed equally imply a redistribution of opportunities, although the shape that such redistribution should take remains contested (Rawls, 2020). Nancy Fraser and many other agents of social justice advocate for education as a public good, from a social justice approach. This approach draws on three dimensions of social justice: redistribution, recognition, and participation.

The essential question the capability approach asks is: 'What substantive freedom enhances the ability of people to help themselves and also influence the world?' Educational equality is conceptualised through the capability approach by focusing on fundamental functionings, promoted by education, that are essential prerequisites for equal participation in society (Terzi, 2007). This, according to Terzi, would consist of equal and effective opportunities and access to these basic functionings (Terzi, 2007). 


\section{Methods}

The main research objective in this study was to investigate ways in which EEA in flood-prone schools can be achieved. The research site is limited to public primary schools in Budalang'i division, in Bunyala Sub-county, Busia County in western Kenya. Budalang'i division is perennially affected by flooding (Opere, 2013). The study applied a convergent mixed-methods approach, using interviews, a survey, and focus group discussions (FGDs) to collect data (Erima, 2020). Fifteen in-depth interviews were conducted with parents and senior school managers (principals and senior teachers) in the selected schools. Eight other interviews were conducted with representatives at the sub-county education office and local government departments, as well as the disaster management department (Erima, 2017). Respondents were selected through a purposive/purposeful sampling strategy, to provide the best information on the population under study. 191 Standard 8 pupils from the five primary schools completed a questionnaire. Five FGDs were also conducted with 10 pupils, selected by class prefects, from each of the five schools. In total, there were 23 interviews and 191 completed questionnaires in the research project. All the questions were derived from the nine indicators of the conceptual framework. No secondary data was used in this research. Qualitative data were analysed using ATLAS.ti, to categorise data into codes and themes. Quantitative data was coded and tabulated using MS Excel and presented using graphs and tables. The four ethical issues: informed consent, confidentiality, anonymity, and the right to withdraw, were also adopted in this study. The study was approved by the Ethics Committee in Education of the Faculty of Humanities, University of the Witwatersrand, Protocol Number: 2015ECE001D.

\subsection{Population and Sampling}

Table 1. Selection of schools

\begin{tabular}{lll}
\hline School & Status about floods & Performance \\
\hline School A & Slightly affected by floods & Low \\
School B & Affected by floods & Good \\
School C & Affected by floods & Average \\
School D & Affected by floods & Fluctuates \\
\hline School E & Severely affected & Very low \\
\hline
\end{tabular}

The five schools were selected using the stratified random sampling strategy across four pre-selected sub-locations, based on the severity of floods and performance. The sampling frame consisted of a school from each category across four locations, as displayed in Table 1 (see Erima, 2017). Respondents were selected using a purposive/purposeful sampling strategy, based on our knowledge of the population. 


\section{Findings}

The broad research question for this study was: How may equitable epistemological access be achieved in flood-prone schools in Kenya? Responses to the research question were guided by the conceptual framework for the research, which categorised the nine indicators into two: school factors and multidimensional school partnerships, see Figure 2 (Erima, 2017). These framed the interview questions and the questionnaire.

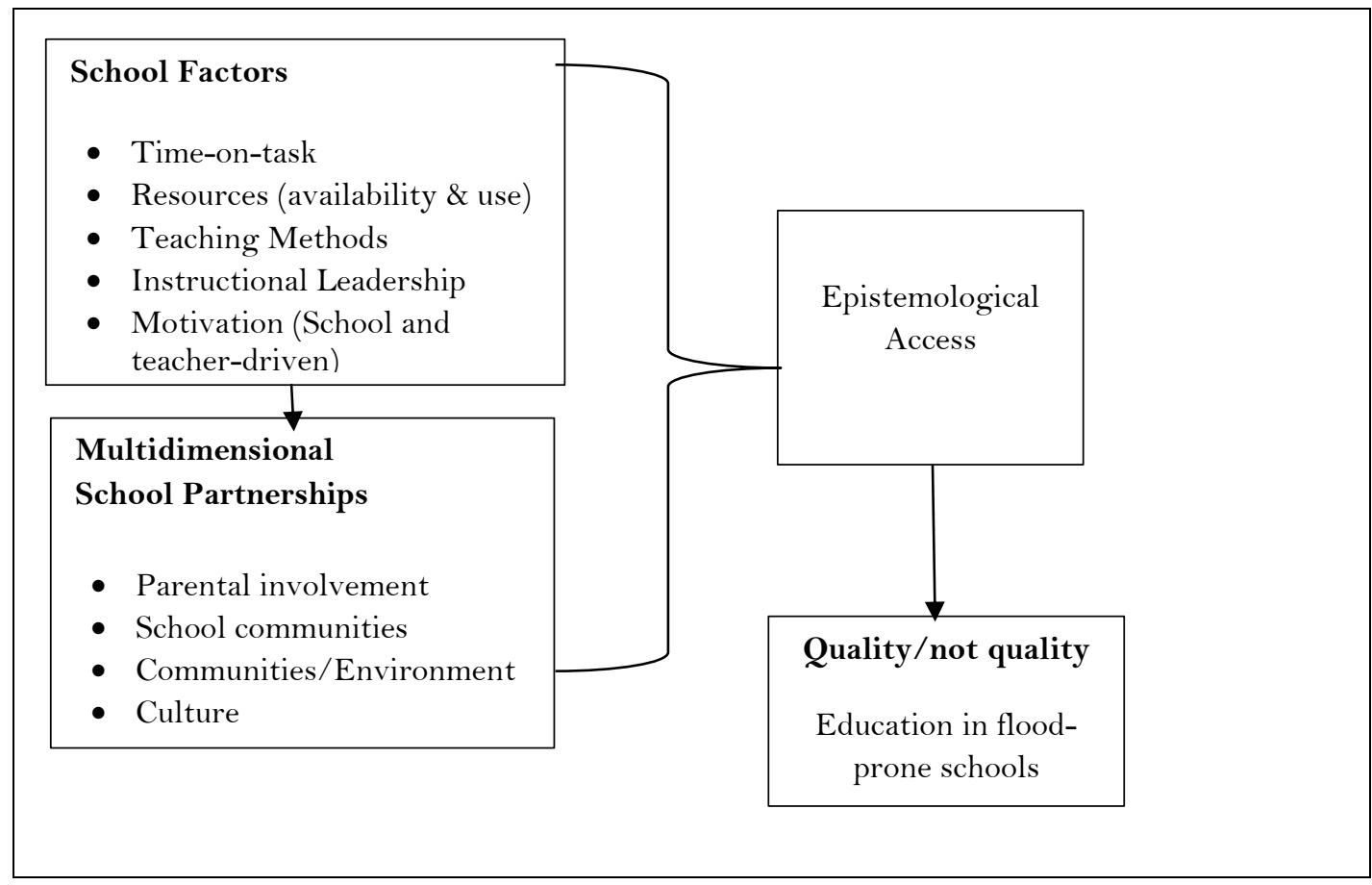

Figure 1. The EA Conceptual Framework

Based on responses from interviews, FGDs, and questionnaires, findings point to two broad categories of indicators that flood-prone schools use in promoting physical and epistemological access to learning. Some are mediated at the school level and some at the teacher or classroom level. Themes were then carved from the two categories. The three school-mediated factors are i) school resources in terms of availability, management and utilisation ii) teacher motivation (schooldriven and self) iii) instructional leadership. Data also revealed that these schools mainly promote EA using classroom or teacher-mediated factors. These are factors that directly relate to learning and teaching, closely linked to the availability of quality teaching and learning materials (school facilities/resources) (Alubisia 2005). They include i) time-on-task and ii) pedagogy (see Figure 2, Erima, 2017). 


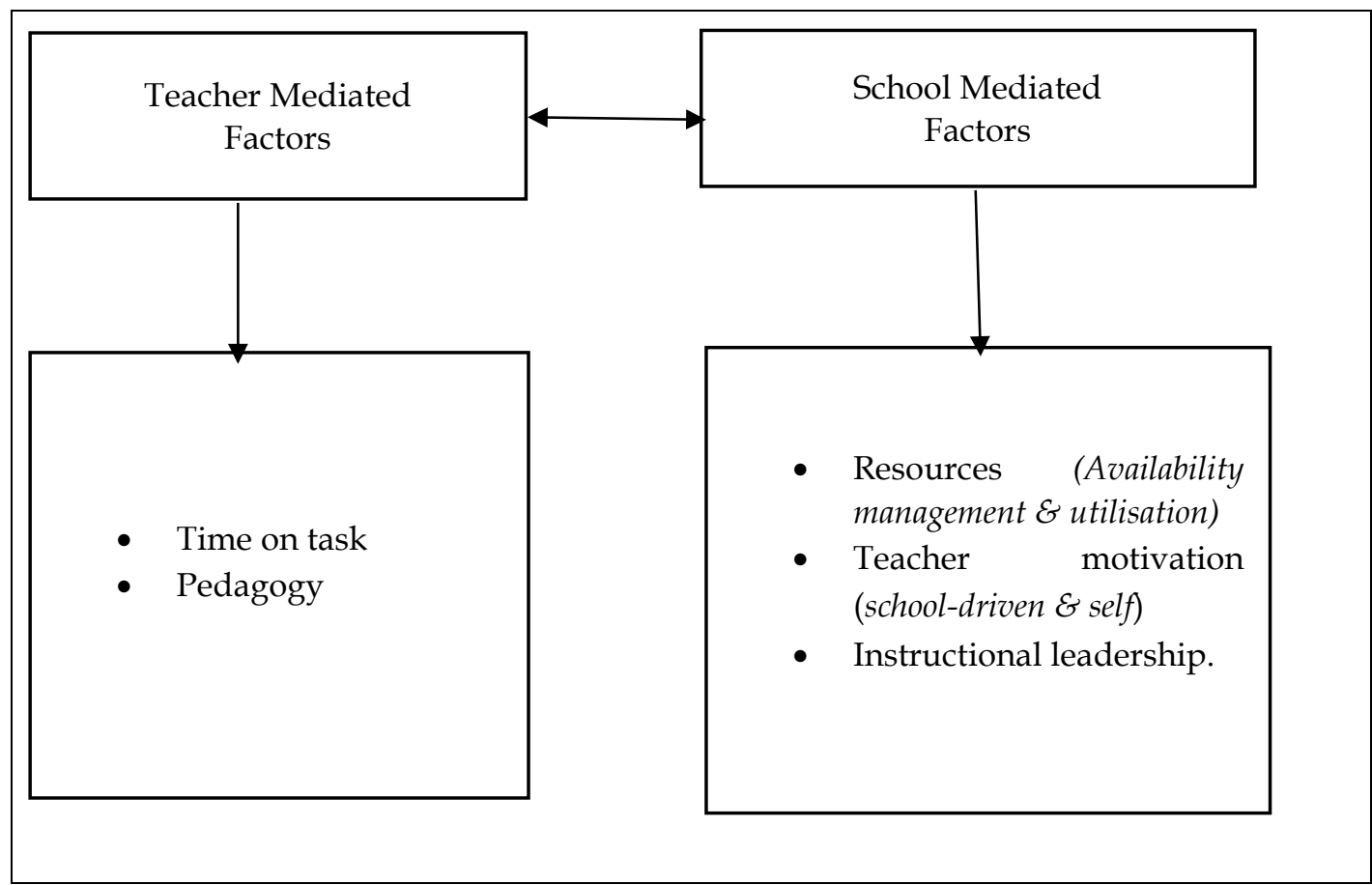

Figure 2. Categories of EA Indicators

\section{School mediated factors and the physical access}

Resources: 'A well-functioning education system requires adequate expenditure and basic infrastructure to support educational outcomes; but these alone will not ensure higher levels of learning' (Chudgar et al., 2015). From data, it emerged that the availability of resources was a major factor contributing to the promotion of physical access. Principals, pupils, and other respondents established that educational resources were important ingredients for academic achievement in their schools. Findings generally suggested inadequate facilities and learning materials as a major and direct problem confronting flood-prone schools. The schools had a few permanent structures and could access learning materials and basic meals to support learning. However, findings suggested a lack of adequate and appropriate conventional, as well as school organisation resources in both measures. Conventional resource measures refer to the availability of textbooks, furniture, technology, electricity, blackboards, a library, and other basic infrastructure, including school buildings. Though schools received funding and tried to supplement their income, through mobilising resources and other income generation activities, it was not enough. Regarding the utilisation and management of resources, there were cases where schools misappropriated funds, while others had learning materials, like books (specifically those on disaster management), lying in the school stores without use.

Motivation: Various research studies show that teachers are not motivated by the need to achieve ideal-oriented goals. Much more specificity is required, with attention being directed towards what precisely motivates teachers, rather than why it motivates them (Evans, 1998). Findings indicated that to promote physical access, schools had incentives in place, as a way to promote their teachers. The biggest challenge with this was that schools tend to work on their own to find 
resources to motivate teachers. It was evident that they tried to provide incentives like meals and rewards, which eventually became unsustainable in the long run. Schools also introduced gains, both monetary and non-monetary, to motivate teachers. The Board of Management (BoM) endeavoured to hire extra teachers to reduce extensive workloads teachers carry, due to extra learning time. The biggest challenge in this strategy lay in the compensation of those teachers' efforts, where schools were forced to turn to the already burdened parents for financial support. Teachers got demoralized, because of the number of working hours coupled with overcrowded classrooms, with little or no learning materials. Borrowing from Leyendecker et al. (2008), the situation had moved from reduced instructional processes to common undemanding outdated methodologies and doubled-up classes, some of which were not attended at all. Besides, it emerged that, due to floods and extensive workloads, teachers did not prepare well for classes - and yet took the blame for poor results.

Instructional leadership: In an effective school, the principal acts as an instructional leader and effectively and persistently communicates that mission to the staff, parents, and students (Lezotte, 2011). Lezotte contends that, in many schools, instructional leadership focuses primarily on the principal and the teachers. Contrary to this approach, the author views leadership as a dispersed concept that should include all adults in the school community, in addition to the teaching staff. This concept is addressed in this study, as an attempt to elucidate that the leadership function embraces a community of shared values, giving identification to what the school community cares about. In addition, we view effective leadership as being situational and contingent on context and circumstances (Male, 2006) and that the selection process for the head teacher should relate the qualities and aptitudes of the candidate to the specific requirements of the school-in this case, floods and learning challenges. From the findings, it was evident that principals understood and applied this practice to promote instructional effectiveness. Schools had and continued to manage, the instructional programme through the principal as the instructional leader. Through this practice, schools in this study understood and embraced this spirit to build the capacity and confidence of their teachers towards their schools. It emerged from the interviews that teachers in the five schools were generally happy with the status quo and appeared to be satisfied with leadership in their schools, mostly because they participated in decision-making and the running of the school. The school climate seemed to be just fine in most schools, as every teacher got a chance to lead in respective areas. Three out of the five principals interviewed rotated responsibility amongst their teachers to build their capacity in different departments, which is positive. However, findings revealed that the standards for instructional leadership focused primarily on the principal and teachers.

\section{Teacher or classroom mediated indicators and epistemological access}

Time-on-task: Learner time-on-task is broadly seen as the time spent on learning activities, which may be significantly affected by interruptions (Maina \& Maringe, 2020). Learner time has a significant positive impact on EA and provides a strong indicator of students' access to learning opportunities (Leyendecker et al., 2008). 
This study revealed a distinct disadvantage for pupils in flood-prone schools, concerning the time they spent actually learning. Both quantitative and qualitative data indicated that there is little engaged time spent on learning in flood-prone schools. It is evident that a significant amount of learning time, close to three months in a year, is lost due to floods.

Based on data, 125 out of the 191 pupils had repeated a class, translating to about $65.4 \%$ cases of repetition across the five participating schools (see Table 2).

Table 2. Cases of repetition: School cross-tabulation

\begin{tabular}{|c|c|c|c|c|c|c|c|}
\hline \multirow[t]{2}{*}{ Repetition } & & \multicolumn{5}{|c|}{ School } & \multirow[t]{2}{*}{ Total } \\
\hline & & A & B & $\mathrm{E}$ & C & $\mathrm{D}$ & \\
\hline \multirow{2}{*}{ Yes } & $\mathrm{f}$ & 35 & 23 & 9 & 24 & 34 & 125 \\
\hline & $\%$ & $28.0 \%$ & $18.4 \%$ & $7.2 \%$ & $19.2 \%$ & $27.2 \%$ & $100.0 \%$ \\
\hline \multirow{2}{*}{ No } & $\mathrm{f}$ & 13 & 14 & 6 & 23 & 10 & 66 \\
\hline & $\%$ & $19.7 \%$ & $21.2 \%$ & $9.1 \%$ & $34.8 \%$ & $15.2 \%$ & $100.0 \%$ \\
\hline
\end{tabular}

Table 3 indicates the reasons for repetition. The biggest cause of repetition, according to data, was 'poor performance', at $46.3 \%$; followed by 'effects of floods', at $26 \%$; and a lack of fees, at $17.9 \%$.

Table 3. Reasons for repetition

\begin{tabular}{|l|l|l|}
\hline Reason & Frequency & Percent \\
\hline Because of fees & 22 & 17.9 \\
\hline Because of floods & 32 & 26.0 \\
\hline Because of poor performance & 57 & 46.3 \\
\hline Lack of a birth certificate & 2 & 1.6 \\
\hline Due to transfer & 8 & 5.7 \\
\hline Parents advice & 4 & 2.4 \\
\hline Total & 125 & 100.0 \\
\hline
\end{tabular}

Poor performance was primarily due to a lack of concentration, lost interest in school, demotivation, or attention to other matters on the part of pupils, teachers, and parents. This is hardly surprising because people would naturally turn to more pressing emergencies when under pressure (e.g. protecting property or fending for means of survival), rather than prioritise education. Forced repetition largely led to dropouts and education wastage.

Data also revealed that, with a tight policy on the school calendar, schools toiled to ensure that the syllabus was completed in standard time through extra learning. Results further revealed a significant effort from schools to enhance time-on-task to promote EA. Principals, senior teachers, and Sub-county education officers agreed to extra learning hours to compensate for lost time during floods. A further result revealed that this was a workable strategy, where teachers committed to teaching extra hours early or late in the day, including weekends. It appeared that schools, pupils, and parents felt they had successfully 
met the set criteria for extra learning time. Some had even constructed basic dormitories, or turned classrooms into dormitories in the evenings, to allow pupils to cover the syllabus. Unfortunately, the Sub-county education office did not coordinate the extra learning in schools: it was fully managed by the school on their terms.

Pedagogy: Appropriate teaching methods embrace both the general teaching methods and practical learning. Teachers' knowledge would encapsulate the effective use of general cognitive theories and philosophies of teaching and learning, as grounding for a more subject-specific readiness and effectiveness (Maringe, 2017). Schools, together with the Sub-county administration, have put in a significant effort to improve teaching methodologies. They organise seminars and workshops on pedagogy to train teachers on how to complete the syllabus in a short time, among other skills. Teachers also do benchmarking and exchange programmes, to learn from each other about how to improve their teaching skills. It emerged that practical teaching in flood-prone schools (learning aids, charts, real objects, cards, etc.) enhanced learning and made it real. Findings further revealed the willingness of teachers to employ proper teaching methodologies, but that they were discouraged by a lack of teaching aids for instruction. Currently, there are neither teaching aids, nor libraries, to support practical learning. In order not to be held accountable for failure, teachers improvised teaching aids and, through concerted efforts, came up with practical ways of teaching. Of interest was that most of the improvised teaching aids worked well, but most were foreign to learners. It was also not surprising that there were notable negative learning effects in schools, where teaching aids were not used.

\section{Discussion of Findings}

Based on the findings, this paper seeks to answer the questions:

1. What human capabilities do schools in flood-prone areas serve and not serve in Kenya?

2. How might a socially just pedagogy enhance human capabilities in flood-prone areas in Kenya?

\section{A capabilities approach towards a socially just education in flood-prone schools}

An adequate level of inputs in an appropriate school would include, the number of teachers, adequate teaching resources, and facilities for the efficiency and effectiveness of the learning process. 'The greater the quality and quantity of inputs, the better the quality of output, which will satisfy the expectation of the society and the government' (Achoka \& Maiyo, 2008, p 157). From findings, it appears that all five indicators discussed are essential strategies to enhance learning and do play an important role in achieving equitable EA in flood-prone schools. Five issues emerge from findings concerning the capabilities approach towards a socially just education for learners in flood-prone schools:

\section{The redistributive justice approach and EA}

Nancy Fraser's tripartite model explains justice in the realm of education using a multidimensional approach of redistribution, recognition, and representation 
(Lepianka, 2021). These are treated as three primary and inextricably interwoven aspects of justice that have broad independent applications in addressing realworld injustices (Fraser, 1999, 2009). The redistributive component is mostly related to justice conceived in distributive terms and seen as resources that can be converted into capabilities (capability inputs). As already mentioned, redistributive justice draws on distributive principles, such as merit or equality, based on a set of material and non-material goods. These factors work towards sustainable livelihoods, economic growth, and access to material and human resources (Tikly \& Barrett, 2011). In the schools under study, the government has succeeded in enrolling students through Free Primary Education (FPE). Other factors notwithstanding, it is evident that this enrolment does not correlate with the schools' capacity, in terms of resources and materials. Emphasis has been put on retaining pupils in schools and the outcomes of the assessment. We agree that improved access to school equals outcomes and equity. However, the question of quality inputs has often been overlooked, especially in these schools. The question of factors, like school feeding programmes, teaching and learning materials, teacher quality, and instruction leadership, all add to the debate on how redistribution and quality can raise performance and improve scores for the socioeconomically disadvantaged. In addition, as materials and other pedagogical inputs are provided, it is fundamental that they are appropriate to the environment (i.e. the recognition of diverse needs in education).

\section{The capability approach: Recognition of different perspectives in education}

Recognition within social justice concerns distinctive perspectives of marginalised groups by dint of ethnic, sexual, and religious orientation in society, among other characteristics (Tikly \& Barrett, 2011). Walker (2008) states that in the learning process, capabilities are not just seen as 'functionings', but also as 'becomings'. Recognition claims therefore can be made from school, while at the same time creating the status of inequalities by meeting specific demands of educational processes, and being sensitive to how diversity in education actively shapes identities. Tikly and Barrett intimate that calling specific attention to the needs of marginalized and excluded learners is key to curricula and the teaching and learning processes that value their way of life (Tikly \& Barrett, 2011). Recognition claims of marginalised groups can be considered to illustrate some of these demands and values, amongst which are those that constitute barriers to access to schools and attainment of quality knowledge-and then converting these to capabilities and functionings. This has happened in some schools in Australia and the USA, where the curriculum has been designed and implemented to accommodate the hybrid history and culture of Native Americans (Tikly \& Barrett, 2011). Another good example exists in North East Uganda, under the Alternative Basic Education for Karamoja (ABEK), East Africa. The programme accommodates nomadic pastoralists' needs and lifestyles through a flexible daily schedule, to allow children to participate in household chores (Tikly \& Barrett, 2011).

To this end, teaching and learning skills need to identify with a people's culture and environment. Learning materials and teaching methodologies in environments prone to floods should be linked to their history and culture to help 
them identify themselves. This should extend to the use of local languages in the early years of primary schools, for a start. New languages of instruction may lead to dropouts, where children may feel culturally alienated and not valued in school. Determining the curricula content is one way through which a society decides the value of education. In this way, learner inputs are easily converted into capabilities (outcomes) that will enable them to live better lives in the future. Recognition of the needs of a people usually links to societal representation.

\section{Education and equal participation in society}

This concerns the component of participatory social justice vis-à-vis education quality. Building on Sen's and Nussbaum's notion of capability, Fraser proposes the idea of public dialogue and debate in education (Erima, 2017). Fraser particularly refers to the extent of exclusion faced by parents and communities in terms of equity and quality education (Tikly \& Barrett, 2011). Going back, formal and informal schooling is central to Sen's capability approach is a moral framework, which specifically emphasises expanding the realm of human agency and effective freedoms (Terzi, 2008). Education is among basic capabilities i.e. among 'a relatively small number of centrally important beings and doings that are crucial to wellbeing' (Sen, 1992, p. 44). That, an understanding of the capability approach is all about a person's capability to live a meaningful life based on the effective opportunities the individual has. This implies living a life, free from the inequalities in well-being, and being able to choose among a set of capabilities, those that $s \backslash$ he has reason to value. Having effective opportunities enables people to 'stand as equals' in societal participation, which contributes to the importance of human rights, equality, and non-discrimination (Terzi, 2008). Achieving the same grade for any two students demonstrates equality. As we might agree, the outcome of these students seems equal, if we look only at functioning. The capability approach, however, requires that we look beneath this outcome at the real freedom or opportunities each student had to achieve what she valued (Walker, 2008). The evaluation of equality needs to consider freedom in opportunities, as much as of observed choices (Walker, 2008). Learners in floodprone schools need both rationality and freedom in their choices (Erima, 2017). Without the assumption of freedom, reason cannot act.

\section{The Expansion of Capabilities in children}

Education plays a crucial role in expanding a child's capacity or ability (Saito, 2003; Unicef, 2018). Capability has to do with what education enables the child to do, whereas capacity is the broadening of the opportunities that the child is exposed to. Sen's approach concerns the importance of the freedom the child will have in the future and not the freedom a child has now because the child must have more freedom when it grows up (Sen, 2002). It is impractical not to expose both skills and content to a child, claiming the future of the child is not known to us yet. It is also not proper to let a child choose what they want to learn, as this may restrict the range of good opportunities in the future. In the same vein, it is not proper to ignore children's capability needs, just because they are children. It is only appropriate that we promote EA in flood-prone schools for the sake of the future of children who, at the moment, depend on us. As long a person's capabilities in terms of their lifespan are considered, the capability approach seems to apply to children (Saito, 2003). Saito argues that education creates a new 
capability for a child, thus making him/her independent. This independence then allows the child to be able to make choices in his/her life (Saito, 2003).

\section{Conclusions and Implications}

It can be argued that, when education plays an essential role in the sense of meeting a basic need, a lack of it constitutes a fundamental disadvantage (Sen, 1992). People have to meet fundamental needs to achieve well-being and so everyone should have goods and services that satisfy their basic needs (Saito, 2003). Depriving children of education during childhood (be it in formal schooling, or informal learning in social interactions) determines a disadvantage that proves difficult, and in some cases truly impossible, to compensate for in later life (Terzi, 2008). There need to be important considerations given to the kind of education that should be provided to individuals, given the complex interrelation they have with the society they inhabit. It follows that an education consistent with enabling people to achieve well-being and allowing the exercise of agency entails the promotion of functionings and capabilities. These pertain to abilities and knowledge that enable the children to become participants in dominant social frameworks, while simultaneously promoting reflection on valued goals.

It should be understood that quality in education goes beyond years spent in school, therefore expansion in educational opportunities alone may not necessarily address quality and capability concerns. Indeed, an effective school would require the input of both financial and material resources, including teacher and pupil characteristics, to produce outcomes. One reason the improvement of the quality of education has been lagging, in most national agendas, is the assumption that, if schools are basically functioning, there is no need to strive to improve on quality. Taking our cue from Tikly and Barrett, 'basic school functioning means that staff and students can be physically present in a school building with classrooms and the minimum of furniture and they are physically, emotionally, and mentally well enough to apply themselves to teaching and learning, i.e. they are not hungry and are in good health' (Tikly \& Barrett, 2011, p. 3). Basic school functioning is a typical setting in the case of floodprone schools, where children attend school in buildings with little or no furniture. It becomes difficult for the relevant authorities to re-invent the wheel in ensuring the quality of schooling in these regions, just because the schools are seen as functioning. The model below indicates how a socially just pedagogy might enhance human capabilities in flood-prone areas (see Figure 3, Erima, 2017). 


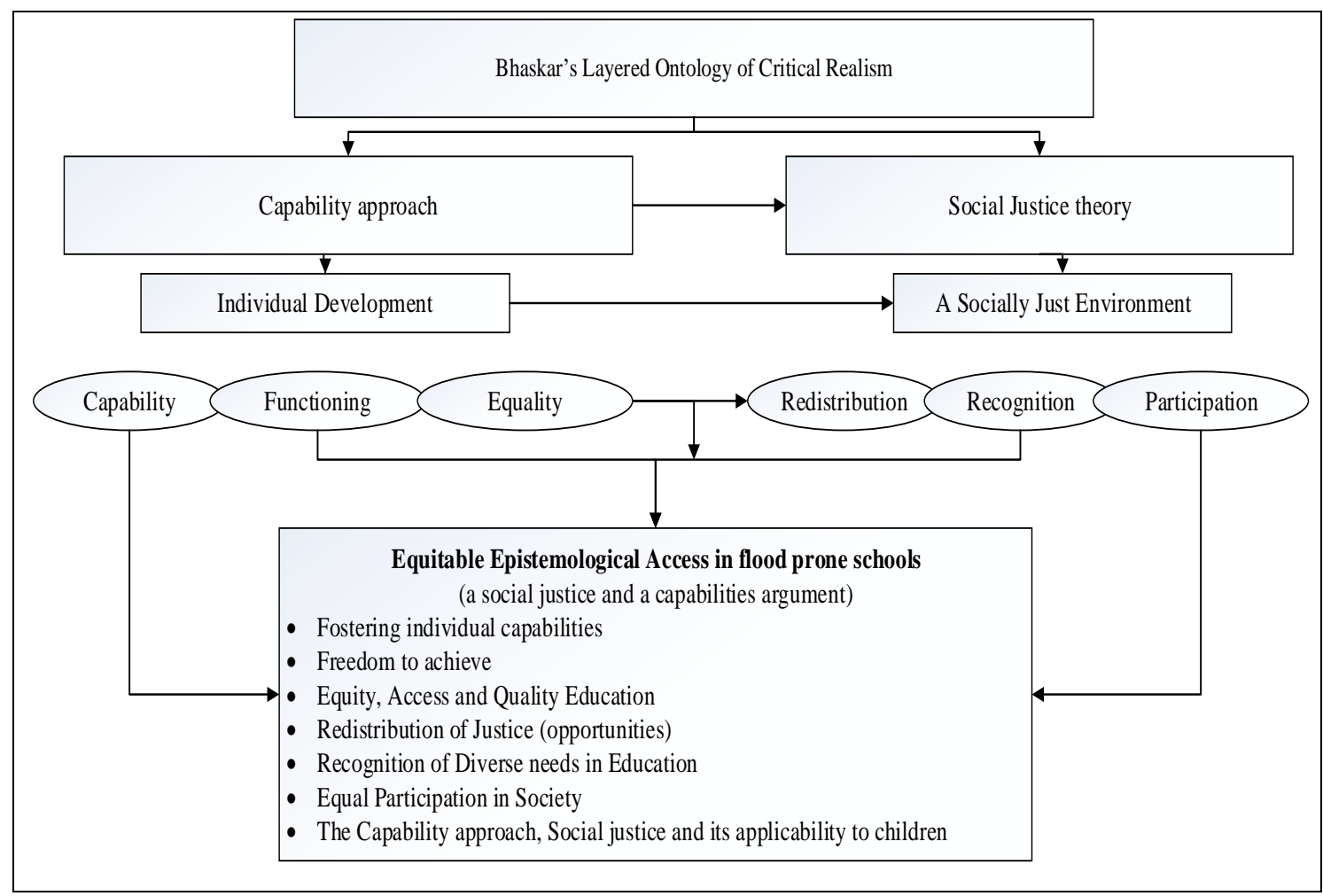

Figure 3. A stratified layered ontology and the capabilities approach towards a socially just education system in flood-prone schools

More often than not, schools prone to floods have been exposed to uniform national assessments of cognitive learning to measure cognitive outcomes. This not only overlooks but does not refer to the learning processes. Where improving the quality of education has been seriously considered, the rationale for investing in quality has simply been seen as a means to increase retention or outcomes (Tikly \& Barrett, 2011). The quality of education has, in fact, declined, as governments have become progressively more successful at increasing enrolments ahead of limited initiatives to improve quality (UNESCO, 2008; Zuze, 2008). This has, in turn, reinforced a tendency, particularly within the human capital theory, to neglect the processes of teaching and learning and the question of how resources get distributed within schools (Tikly \& Barrett, 2011).

In Levin's (2003) words, equitable quality education is important to learners for three reasons: Firstly, in line with Sen's capability theory, there is surely a human rights imperative for all people to have a reasonable opportunity to develop their capacities and to participate fully in society (Abdu \& Joshua, 2019). Secondly, according to Nancy Fraser, insofar as opportunities to learn are not distributed fairly, there will be an under-utilisation of talent, as some people will not develop their skills and abilities-with consequent loss, not only to them but to the society generally. Lastly, higher levels of education are associated with almost every positive life outcome: not only with improved employment and earnings but also with health, longevity, successful parenting, civic participation, and so on. Education leads to the knowledge, skills, and understandings required to maximise learners' freedom in employment, for their development as individual 
personalities, and for producing informed and critical democratic citizens (Terzi, 2008; Walker, 2008). The capability approach, therefore, determines how EA is viewed and sees human beings as productive beings, with ethical and political concerns (Du Plooy \& Zilindile, 2014). A good education system should play a role in expanding the child's capabilities and make them autonomous in the future.

\section{Limitations}

The perspectives provided should be considered in light of the limitations of this study, which draws data from five flood-prone schools. This sample is very small compared to the population and may undermine the accuracy of findings. Secondly, the study did not focus on the EA of children beyond the primary school level. Individual pupil development may change, as pupils progress to higher levels of learning. The transition and educational progress of pupils may play out differently in secondary schools which have more boarding facilities. Finally, the nine indicators were pre-determined and contextualised from the literature. The study did not look beyond for other factors affecting learning in these schools, but only the nine considered as those that provide the essential rationale for EA towards capability development. As a consequence, findings can be generalised only to an extent, based on a specific location and period.

\section{Conclusion}

In this paper, we have engaged with critical realism as the philosophical basis, premised on Sen's capability approach and Nancy Fraser's social justice framework, to explore how theory can be used to explain the nature of schooling in disadvantaged communities. In so doing, we have justified the importance of the development of capabilities in a socially just environment and their relevance to equitable EA in flood-prone schools. The paper has also explored capabilities and freedom about children's education, as well as capabilities concerning autonomy and education systems.

For us, there is a need not only to develop capabilities in our education systems but to do so using a socially just approach. Attainment of meaningful learning implies fairness in the distribution of available resources; the access to these resources; and the distribution of existing opportunities. This then enables disadvantaged learners to benefit from education as a space for social transformation. The onus to transform schools, therefore, lies with educators, policymakers, and the government. This paper becomes a starting point to test areas of further research on capabilities and social justice in disadvantaged schools. It also raises the question of whether the policy should be changed from untested evidence. 


\section{References}

Abdu, H., \& Joshua, S. (2019). Quota system and University Admission in Nigeria: Equity Perspective. https://centrelsd.org/wpcontent/uploads/2020/07/QuotaSystem-and-University-Admission-in-Nigeria-Equity-Perspective-edited.pdf

Achoka, J. S. K., \& Maiyo, J. (2008). Horrifying disasters in Western Kenya; Impact on education and national development. Education Research and Review, 3(3), 154-161. https://doi.org/10.5897/ERR.9000186

Alkire, S. (2013). Choosing dimensions: The capability approach and multidimensional poverty. In The many dimensions of poverty (pp. 89-119). Palgrave Macmillan, London. https://doi.org/10.1057/9780230592407_6

Alubisia, A. (2005). UPE myth or reality: A review of experiences, challenges and lessons from East Africa. OXFAM/ANCEFA, London.

Cheng, M. (2017). Reclaiming quality in higher education: a human factor approach. Quality in Higher Education, 23(2), 153-167. https:// doi.org/10.1080/13538322.2017.1358954

Chudgar, A., Chandra, M., Iyengar, R., \& Shanker, R. (2015). School resources and student achievement: Data from rural India. Prospects, 45(4), 515-531. https://doi.org/10.1007/s11125-015-9360-3

Du Plooy, L., \& Zilindile, M. (2014). Problematising the concept epistemological access with regard to foundation phase education towards quality schooling. South African Journal of Childhood Education, 4(1), 187-201. https:// scholar.google.com/citations?user=P-jQ7sIAAAAJ\&hl=en

Erima, G. (2017). Epistemological access in flood-prone primary schools of Western Kenya [Doctoral dissertation, University of the Witwatersrand]. South Africa]. https://pdfroom.com/books/thesis-for-the-degree-of-doctor-of-philosophyepistemological-access-in-flood-prone-primary/Xn2GJZX7gxV

Erima, G. (2020). The Meaning of Social justice for Rural Education: Access, Participation and Achievement. In Rurality, Social Justice and Education in Sub-Saharan Africa Volume I (pp. 151-175). Palgrave Macmillan, Cham. https:/ / doi.org/10.1007/9783-030-57277-8

Evans, L. (1998). Teacher morale, job satisfaction, and motivation. Sage.

Fraser, N. (1999). Social justice in the age of identity politics: Redistribution, recognition, and participation. Culture and economy after the cultural turn, 25-52. http:/ /www.wz-berlin.de

Fraser, N. (2009). Scales of justice: Reimagining political space in a globalizing world (Vol. 31). Columbia University Press.

Glewwe, P. (2002). Schools and skills in developing countries: education policies and socioeconomic outcomes. Journal of economic literature, 40(2), 436-482. https:// doi.org/10.1257/002205102320161258

Lepianka, D. (2021). Less-standard claims to justice through the lens of media debates on minority education. Theory and Research in Education, 19(2), 127-147. https:// doi.org/10.1177/14778785211028400

Levin, B. (2003). Approaches to equity in policy for lifelong learning. Education and Training Policy Division, OECD. Paris: OECD.

Leyendecker, R. W., Ottevanger, W., \& van den Akker, J. (2008). Curricula, examinations, and assessment in secondary education in Sub-Saharan Africa. Africa human development series. https://doi.org/10.1596/978-0-8213-7348-4

Lezotte, L. W., \& Snyder, K. M. (2011). What effective schools do: Re-envisioning the correlates. Solution Tree Press. 
Maina, G. E., \& Maringe, F. (2020). Epistemological Access in Disadvantaged Schools: A Case Study of Flood-Prone Rural Schools in Western Kenya. In Inclusion as Social Justice (pp. 14-35). Brill Sense. https://doi.org/10.1163/9789004434486_003

Male, T. (2006). Being an effective head teacher. SAGE.

Maringe, F. (2017). Creating Opportunities for a Socially Just Pedagogy: The Imperatives of Transformation in Post-Colonial HE Spaces. In Transforming Teaching and Learning in Higher Education (pp. 59-78). Springer International Publishing. https://doi.org/10.1007/978-3-319-46176-2_4

McLean, M., \& Walker, M. (2012). The possibilities for university-based public-good professional education: a case-study from South Africa based on the 'capability approach'. Studies in Higher Education, 37(5), 585-601. https:// doi.org/10.1080/03075079.2010.531461

Masese, A., Opiyo, R., Okayo, J., \& Ombui, N. M. (2012). Impact of floods on attainment of education for all (EFA) and vision 2030 in Nyando Basin. Kisumu County International Journal of Disaster Management and Risk Reduction, 4(2), 19-31.

Miletzki, J., \& Broten, N. (2017). An Analysis of Amartya Sen's: Development as Freedom. Macat Library. https:// doi.org/10.4324/9781912281275

Munyi, C. M., \& Orodho, J. A. (2015). Wastage in schools: What are the emerging internal efficiency concerns in public primary schools in Kyeni Division, Embu County, Kenya? Developing Country Studies, 5(6), 135-146.

Nussbaum, M. C. (2001). Women and human development: The capabilities approach (Vol. 3). Cambridge University Press. https://doi.org/10.1017/CBO9780511841286

Okuom, H. A., Simatwa, E. M., Olel, M. A., \& Wichenje, K. M. (2012). Assessment of factors that contribute to repetition and dropout of pupils in primary schools in flood prone areas of Nyando District, Kenya: An analytical study. Educational Research, 3(2), 190-201.

Opere, A. (2013). Floods in Kenya. In Developments in Earth Surface Processes (Vol. 16, pp. 315-330). Elsevier. https:/ / doi.org/10.1016/B978-0-444-59559-1.00021-9

Pendlebury, S. (2009). Meaningful access to basic education. South African child gauge, 2429.

Rawls, J. (2020). A theory of justice. Harvard university press. https://doi.org/10.4159/9780674042605

Saito, M. (2003). Amartya Sens capability approach to education: A critical exploration. Journal of philosophy of education, 37(1), 17-33. https://doi.org/10.1111/14679752.3701002

Sen, A. (2002). Rationality and freedom. Cambridge, MA: Harvard University Press.

Sen, A. (1999). Freedom as development. New York.

Sen, A. (2017). Collective choice and social welfare. Harvard University Press. https://doi.org/10.4159/9780674974616

Terzi, L. (2007). Capability and educational equality: The just distribution of resources to students with disabilities and special educational needs. Journal of Philosophy of Education, 41(4), 757-773. https:// doi.org/10.1111/j.1467-9752.2007.00589.x

Terzi, L. (2014). Reframing inclusive education: Educational equality as capability equality. Cambridge Journal of Education, 44(4), 479-493 https://doi.org/10.1080/0305764X.2014.960911

Tikly, L., \& Barrett, A. M. (2011). Social justice, capabilities and the quality of education in low income countries. International journal of educational development, 31(1), 3-14. https://doi.org/10.1016/j.jjedudev.2010.06.001 
Unterhalter, E. (2007). Gender equality, education, and the capability approach. In Amartya Sen's capability approach and social justice in education (pp. 87-107). Palgrave Macmillan, New York. https://doi.org/10.1057/9780230604810_5

UNESCO, P. (2008). UNESCO, a. Global Monitoring Report. Education for All by 2015: Will we make it?

Unicef. (2018). Learning through play: Strengthening learning through play in early childhood education programmes. LEGO FOUNDATION.

Walker, M. (2008). Human capability, mild perfectionism and thickened educational $\begin{array}{llll}\text { praxis. Pedagogy, Culture \& Society, } 16(2), & 149-162 .\end{array}$ https://doi.org/10.1080/14681360802142112

Zuze, T. L. (2008). Equity and effectiveness in East African primary schools [Doctoral dissertation, University of Cape Town]. South Africa. http:/ / citeseerx.ist.psu.edu/viewdoc/ download?doi=10.1.1.1004.4300\&rep=rep $1 \&$ type $=$ pdf 